\title{
The Role of Art Education in the Improvement of Employment Competitiveness of Deaf College Students*
}

\author{
Fang Lan \\ College of the Special Education \\ Leshan Normal University \\ Leshan, China 614000
}

\begin{abstract}
As the special education flourishes, deaf college students have become an important part of higher education in China. The smooth employment of deaf college students is not only an embodiment of education level in colleges and universities (institutions), but also related to the family happiness of deaf students, and also a significant way for deaf students to realize their personal and social value. The development of extensive art education in deaf students is the need to promote the improvement of art vocational skills of deaf students, shape their healthy personality, enhance their employment competitiveness and achieve their professional goals.
\end{abstract}

Keywords-deaf college student; art education; employment competitiveness

\section{INTRODUCTION}

In recent years, China has made a substantial development in special education, and an increasing number of the disabled have the opportunity to receive higher education. According to the official data released by China Disabled Persons' Federation, from 2011 to 2016, the number of provinces and cities setting up higher education schools (institutions) for the disabled increased from 13 to 15 . The number of enrollment of undergraduates increased from 178 to 654, and number of enrollment of junior college student increased from 474 to 791. According to the survey and statistics for the enrollment specialties by means of single examination and separate enrollment for hearing-impaired college students in 2007 and 2008 in 15 colleges and universities including Tianjin University of Technology, Changchun University, Beijing Union University, Chongqing Normal University, Zhengzhou Normal University, Nanjing Normal University of Special Education, Leshan Normal University and other universities, 11 universities opened art design majors, and 5 universities set up fashion design majors, and 8 universities opened painting and visual communication design majors, which shows the development of art education has become one of the consensus in the higher education for the deaf in China.

* Fund Program: Key Project of Ideological and Political Center of Sichuan Leshan Normal University, Project Name: Cultivation of Hearingimpaired Students in Colleges and Universities Based on the Integration of Disabled and Healthy Concepts, Project No.: S16029.

\section{DEMAND FOR THE ARTISTIC LITERACY OF DEAF COLlEGE STUDENTS IN THE CURRENT JOB MARKET}

In China, the government and society have been paying great attention to the employment of special groups of the disabled including the deaf. China Disabled Persons' Federation, National Development and Reform Commission, Ministry of Civil Affairs, Ministry of Human Resources and Social Security of the People's Republic of China and other departments have successively issued the 13th Five-Year Plan for the Improvement of Employment of the Disabled, Opinions on Supporting the Independent Employment and Entrepreneurship of Disabled and other documents. Meanwhile, China Disabled Persons' Federation also conducts regular and irregular short-term skills training, and employers also provide a pre-job training according to job nature. However, it is easy to see from the survey of job market for the deaf that there are several new trends in the current job market for the deaf:

\section{A. The Demand for Art Vocational Skills of Deaf College Students in Job Market Is Increasing Year by Year}

For a long time, the deaf mainly work as cleaner, hotel attendants and assembly line workers with low technical, repetitive and mechanical working content, with high labour intensity and low wage and treatment. At present, this type of job is overcrowded, besides, and most of the deaf who have received higher education believe that these jobs can be done without college diploma and are of little significance. Then, there is the phenomenon of "being unwilling to take a lower one".

With the development of special education, the excellent quality of deaf college students in the art fields of music dance, art creation and animation design have gradually aroused wide public concern from the society and attracted the attention of employers. Therefore, more skilled jobs are needed in the job market for deaf college students, such as animation production, art design, fashion design, senior pastry cook, senior chefs, full-time actors of disabled arts groups, and so on. Employers still seek this kind of graduates with excellent artistic attainments with eagerness. 


\section{B. The Demand for Compound Deaf College Students in the Talent Market Is Increasing Year by Year}

Social prejudice against the deaf makes people often put the deaf in the category of vulnerable and special groups. Some people even unilaterally think that the deaf are hard to communicate, ideologically extreme and inconvenient to manage, which artificially makes it difficult for deaf students to obtain fair employment opportunities. At present, the state provides a lot of guarantees and preferential measures for the employment of the disabled including the deaf through financial means such as taxation. Some employers employ deaf college students for tax avoidance, while others employ deaf college students according to job nature. However, regardless of the reasons for employers to hire students, their first choice is still compound talents with outstanding professional skills, sound personality, and high social integration. The deaf college students are skilled in some kinds of work, develop their overall quality, and become a spiritually independent, perfect in personality, disabled but useful, wellbehaved, self-reliant citizen. They shoulder a certain family and social responsibility, can reduce the burden on the family economy, generate income for the work unit, and better integrate into the society. This is the common expectation of the whole society and also the expectation of talent market for deaf college students.

\section{The Demand for Deaf Teachers in Primary and Secondary Special Schools Increases}

In 2016, Reply from the Ministry of Education on the No. 9428 Recommendation of the Fourth Session of the 12th National People's Congress (Teaching Recommendation [2016] No. 575) was released, and it intended to authorize Sichuan to carry out a pilot for hearing disabled people to take part in primary and secondary school teacher qualification examinations. Over the past two years, some provinces and cities have made considerable progress in exploring and implementing the recognition of teacher qualification for deafmutes. For example, deaf-mute teachers from Sichuan, Jiangsu, and Tianjin have successively obtained teacher qualification certificates according to regulations. This means that the state and society have highly affirmed the contribution and achievements of deaf teachers in deaf education, and the education departments will pay more attention to and train deaf teachers in education and teaching. For example, Beijing Union University, Chongqing Normal University, Zhengzhou Normal University, Suihua University, Leshan Normal University and other universities have clearly written the "cultivation specialized special education teachers who are engaged in teaching and management of hearing impairment education with their own artistic expertise" into the professional training position of deaf students. It means that with the gradual obtainment of teacher certification for the deaf, more deaf college students will take on teacher post in special education schools.

\section{The Role of ART EduCATION In CULtivating} EMPLOYMENT COMPETITIVENESS OF DEAF STUDENTS

China has always highly value youth art education. In 2014, the Ministry of Education issued Several Opinions on
Promoting the Development of Art Education in Schools. It put art education in a very important position, fully affirmed the role of art education in the education of teenagers' aesthetic cultivation, innovation consciousness, and all-round development of morality, intelligence and physique, made it clear that art education had a strong transcendence, played an irreplaceable role in the formation and improvement of students' sound personality, and was an indispensable and important content of quality education [1] [2].

\section{A. Art Education Contributes to Cultivating the Functional Skills of Deaf Students}

The Vocational Education Law of the People's Republic of China indicates that vocational education is an important part of the national education cause and an important way to promote economic, social development and employment. Currently, the relevant colleges and universities mostly take employment as the orientation, and offer majors for deaf students according to the social needs and their physical and mental characteristics. Colleges and universities strengthen the education of art vocational skills such as music and dance, artistic creation, animation, pastry cook and cooking, which not only gives full play to the advantages of keen vision and taste of the deaf, but also taps and cultivates their artistic potential. Interest is the best teacher, and the combination of interest and occupation will also reflect the personal value, thus promoting the formation of professional self-identity of deaf college students.

\section{B. Art Education Is Conducive to Fostering Teamwork and Social Integration Ability of Deaf Students}

Due to physical absence, deaf students may lose hearing and also become "mute", so they have lost the opportunity to communicate smoothly with normal people. They receive a small amount of information and the information may be biased or even completely inconsistent with objective facts. As a result, the deaf are usually more introverted and passive, and dare not express their own voices to the outside world. In interpersonal communication, some deaf college students have doubts and are sensitive and tend to flinch. They fear that others will look down on them and deliberately avoid normal social interactions [3].

Dance and other art troupe activities focus on teamwork, which enhances the communication between the deaf college students, cultivates the tacit understanding between the students, and gives them more opportunities to contact the society, understand the society and adapt to the society.

\section{Art Education Is Beneficial to Cultivating Deaf Students' Innovative Spirit}

1) Cultivation of innovative thinking ability: Art itself emphasizes the freedom of spirit and thoughts and novelty of form, and requires us to get rid of the stale and bring forth the fresh. The process of art education itself is the process of pursuing innovation, which is of great help to the training of deaf students' creative thinking ability.

2) Cultivation of innovation and entrepreneurship ability: Art education is to cultivate deaf college students' humanistic 
quality, and constantly promotes deaf students to develop the ability to feel beauty, discover beauty and create beauty. Besides, under art education, deaf students will achieve mastery through a comprehensive study, use relevant theoretical knowledge to solve problems, tap their own potential, actively upgrade working methods, broaden employment and entrepreneurship ideas, and embark on the road of innovation and entrepreneurship.

\section{Art Education Is Conducive to Cultivating Deaf Students' Correct Professional Ethics}

Sukhomlinskii once said: "Beauty is a powerful source of pure morality, enrich spiritual life and healthy body. The most fundamental function of aesthetic education is to teach children to see the nobility, kindness and sincerity of spirit from the beauty of the surrounding world, including nature, art and interpersonal relations, and to establish and create their own beauty on this basis". Art education is conducive to cultivating deaf college students to be positive and kind and to seek truth, goodness and beauty, and helpful to guide teenagers to inherit and carry forward Chinese excellent traditional culture consciously. It can be seen from this that it has a strong ability to cultivate the moral sentiment of deaf college students. A good aesthetic taste will guide them to distinguish right from wrong and tell black from white, so as to form a correct world view and outlook on life and also establish a good professional ethics.

\section{WAYS TO IMPROVE THE LEVEL OF ART EDUCATION FOR DEAF COLLEGE STUDENTS}

China has achieved good results in art education for the disabled. China Disabled Persons' Federation, the Ministry of Education, Ministry of Civil Affairs, Ministry of Culture and the State Administration of Press, Publication, Radio, Film and Television of the People's Republic of China have jointly organized nine national art festivals of the disabled. According to the statistical bulletin of development of the disabled in China in 2017 [No.24 of CanLianFa (2018)], by the end of 2017 , a total of 6,740 cultural week activities for the disabled had been carried out at the provincial, prefectural and county levels. The National Disabled Persons' Federation at provincial and prefectural levels held 640 cultural and artistic competitions and exhibitions for the disabled, with 281 art troupes for the disabled. In the primary and secondary special education schools, the art education forms of dance, handicraft production and painting for the deaf are developing very well. In the higher education stage of deaf college students, we should not only continue to strengthen the further construction of the art knowledge system for deaf students, but also cultivate applied talents with good professional awareness and morality, art theory accomplishments, and solid professional knowledge and skills.

\section{A. Improving the Methods and Means of Classroom Teaching for Deaf College Students}

Due to the special physiological reason and living in closed special education school for a long term, in the special growth environment, deaf students have certain modes of thinking and study habits different from normal college students, so colleges and universities should conduct education and teaching reform based on the learning characteristics of deaf students and do more research on teaching methods and means. In fact, deaf students have strong visual ability, practical ability and image thinking. But the existing textbook materials of colleges and universities attach equal importance to theory and practice, have a high demand for logical thinking, so the teaching methods for normal college students are not necessarily suitable for deaf students. This requires teachers to forwardly understand the learning rules of deaf students, actively explore and compile appropriate textbooks, visually present abstract knowledge points such as concepts and theorems, and carry out experiential teaching and interactive teaching. Teachers also should adopt modern educational technology as much as possible, use multi-media, laboratories and teaching aids, and carry out multiform teaching activities.

\section{B. Combination of Basic Artistic Quality Education and Art Vocational Education}

1) Development of art skill education : Art education is the intelligence-inspiring education for deaf students. It can help the deaf discover their advantages of "quick-sightedness and light hand", know their own strengths and then get rid of inferiority complex, and establish self-confidence that competes with ordinary people in the stage of art. Therefore, deaf students of any major have the same art education courses and goal as ordinary college students in the direction of art education. We should carry out basic art literacy education among deaf college students, cultivate sentiment, and promote the all-round development of virtue, intelligence, body and beauty. For example, we can open manual classes, physical training classes, dance classes, art classes, and so on.

Currently, although we have made good results in selecting deaf college students in the form of single examination and separate enrollment, in fact, some deaf students choose art majors not because they love arts. They usually carry out assault training for art sketching and painting from life to cope with the exam. Therefore, colleges and universities must first understand the students' ideological situation, and then conduct stratified and classified teaching based on the actual situation of students, and teach students in accordance of their aptitude. They should not only have strict requirements for them, but also subtly cultivate their anti-frustration ability and willpower, enable them to experience the happiness of mastering one or more art skills, and also lay $\mathrm{s}$ solid foundation for them to better integrate the society and go on the way of employment and entrepreneurship.

2) Development of art vocational education: The National Vocational Qualification Certificate is the symbol of possessing professional qualifications, and the National Vocational Skills Certificate represents the level of employment skills. Taking employment as the orientation, we should strengthen the occupational awareness of the students, standardize their professional habits, and encourage them to actively obtain various national vocational qualification certificates and national vocational skills certificates. In the national vocational skill certificate of art, we can encourage 
deaf students to take graphic designer, network editors, 3D renderings designers, animation designers, CAD drafters, animation drafters, web designers, photographers, art editors and designers as their own career goals.

Besides, the teacher certification for deaf students gradually loosens requirements on standard Chinese, while the assessment of artistic accomplishment on deaf teachers is still the focus. In terms of students education in the primary and secondary special education schools, art and culture course is an important teaching content, and "cultivating virtue with art and improving wisdom with art" is the principle that many special education schools adheres to. Only by cultivating special education teachers with rich artistic literacy and strong artistic education skills can they have working competency required by special education teacher post in primary and secondary schools.

\section{Strengthening Art Practice Education}

The practical experience of the second classroom in colleges and universities at home and abroad proves that it is an extension of the first class as well as an effective and useful supplement to the first class. We should establish and improve the second classroom management system of schools, provide financial and venue guarantee for the second classroom activities, strengthen supervision and management of the second classroom implementation, offer students colorful art education information and platforms, and create an elegant cultural and artistic atmosphere in campus. Meanwhile, it also helps the mainstream society to better understand the learning and living conditions of deaf students, understand the world of deaf people, and promote them to create a more relaxed social environment for the growth of deaf students, so as to form a good social atmosphere of caring for and helping the disabled.

1) Deaf students plus art performing group: Art associations are the most distinctive scenery line in the carrier of campus culture in colleges and universities as well as the mass organizations that college students like to join in. We should employ professional instructors, and form art associations among deaf students based on their personal hobby and specialty, such as calligraphy association, chess association, photography association, dance associations, engraving association, situational drama performance association, cooking enthusiasts association, and so on. We also conduct rehearsals of art programs such as collective dances and essays all the year round, and regularly carry out various exchange activities inside and outside the school, which not only enhances the friendship between deaf students, expands their artistic horizons, develops the spirit of teamwork among deaf students, but also greatly improves their artistic accomplishment.

2) Deaf students plus art practice team: The development of activities bringing art and culture to the countryside and "home delivery" teaching in rural areas, communities, schools or enterprises by using spare time and winter and summer vacation is an important part of practical education in colleges and universities and the best way for college students to reach the grassroots level and understand the status quo of economic and cultural construction in basic level. This is especially important for deaf students who are in isolation and confinement for a long time. Colleges and universities can rely on communities, schools and other institutions to build a platform for the art practice of deaf students, so that deaf students "go out", personally participate in various arts activities in basic level, investigate the social needs of art vocational skills, understand the gap of art vocational skills, and experience the active role of artistic knowledge in social, economic and cultural construction. In this way, it not only promotes students to apply what they have learned, and consciously integrates art theory with practical work, but also enhances students' professional identity and professional well-being.

\section{Strengthening Foreign Exchanges and Cooperation}

1) Vertically strengthening coordination and communication with the Disabled Persons' Federation and education authorities at all levels: The smooth employment of the deaf heavily depends on the employment security and career development system constructed and perfected by the government. In promoting the employment of deaf college students, colleges and universities should establish a good communication mechanism with relevant government departments.

According to the Articles of China Disabled Persons' Federation, the duties of China Disabled Persons' Federation are mainly to provide personal files, labor and employment services for the disabled. The cooperation between colleges and universities and China Disabled Persons' Federation can provide more and better support for rehabilitation training and employment guidance training for deaf students. The education authorities are the school's direct management and guidance organization. The enhancement of coordination and communication can provide more policy financial guarantee to tackle difficult problems in the development of universities, so that universities can better follow education teaching rules, meet the growth needs of the deaf students, and meet the expectation of the deaf family and society for high quality education. Besides, it can also provide a full and accurate theoretical basis and practical test results for government decision-making.

2) Horizontally consolidating research on the job market for deaf students: Colleges and universities should conduct extensive market research and timely grasp the changes in the market demand for the deaf talents with art vocational skills. For one thing, colleges and universities should adjust their specialty settings taking employment as the orientation to match the needs of the market, eliminate the structural contradictions between employment supply and demand, strengthen the links with relevant enterprises and units, and strive to conduct "order-type" cultivation mode to realize seamless docking between schools and employers; for another, to open channels, colleges and universities should update the dissemination means of modern information, provide employment information to deaf students through multiple 
channels, carry out personalized career planning and employment guidance, and help them to get on the job position smoothly and support themselves.

\section{CONCLUSION}

Based on the above, art education occupies an important position in the cultivation of compound deaf students, and it is also an important part of the cultivation of deaf students' employment competitiveness. In the process of training deaf students, colleges and universities pay high attention to art education, and constantly upgrade the teaching methods of art education, so that art education runs through the first classroom and infiltrates the second classroom. Only in this way can we cultivate deaf talents with solid professional skills, all-round development of morality, intelligence, body and beauty, and sound personality for China.

\section{REFERENCES}

[1] Chen Yi. Art Education is An Important Part of Quality Education.People's Daily (April 29, 2014, Edition 07). (in Chinese)

[2] Wang Juan. Common Psychological Problems, Causes and Educational Countermeasures of Deaf College Students. Education and Vocation P91.2012. (in Chinese)

[3] Ma Zhibo, Shi Qi. The Promotion of Art Education to the Comprehensive Quality of College Students. Education and Teaching Forum P27. Issue 35, August 2018. (in Chinese) 